\title{
The existence and uniqueness of fractional boundary value problems of the Riesz-Caputo differential equations with nonlocal conditions
}

şuayip toprakseven ${ }^{1}$

${ }^{1}$ Artvin Coruh Universitesi

November 17, 2020

\begin{abstract}
By using the fixed point theorems, we give sufficient conditions for the existence and uniqueness of solutions for the nonlocal fractional boundary value problem of nonlinear Riesz-Caputo differential equation. The boundedness assumption on the nonlinear term is replaced by growth conditions or by a continuous function. Finally, some examples are presented to illustrate the applications of the obtained results.
\end{abstract}

\section{Hosted file}

suayipAMA_.pdf available at https://authorea.com/users/376594/articles/493504-the-existenceand-uniqueness-of-fractional-boundary-value-problems-of-the-riesz-caputo-differentialequations-with-nonlocal-conditions

\section{Hosted file}

suayipAMA.tex available at https://authorea.com/users/376594/articles/493504-the-existenceand-uniqueness-of-fractional-boundary-value-problems-of-the-riesz-caputo-differentialequations-with-nonlocal-conditions 
figures/numericalsolution13/numericalsolution13-eps-converted-to.pdf 